\title{
Regulation of Motility in Erwinia carotovora subsp. carotovora: Quorum-Sensing Signal Controls FIhDC, the Global Regulator of Flagellar and Exoprotein Genes, by Modulating the Production of RsmA, an RNA-Binding Protein
}

\author{
Asita Chatterjee, Yaya Cui, Pranjib Chakrabarty, and Arun K. Chatterjee \\ Division of Plant Sciences, 108 Waters Hall, University of Missouri, Columbia 65211, U.S.A.
}

Submitted 18 January 2010. Accepted 21 May 2010.

\begin{abstract}
Erwinia carotovora subsp. carotovora causes soft-rotting (tissue-macerating) disease in many plants and plant organs. Although pectinases are the primary determinants of virulence, several ancillary factors that augment bacterial virulence have also been identified. One such factor is bacterial motility. Flagellum formation and bacterial movement are regulated in many enterobacteria, including $E$. carotovora subsp. carotovora, by FlhDC, the master regulator of flagellar genes and FliA, a flagellum-specific $\sigma$ factor. We document here that motility of $E$. carotovora subsp. carotovora is positively regulated by the quorum-sensing signal, $N$-acylhomoserine lactone (AHL), and negatively regulated by $\operatorname{RsmA}$, a post-transcriptional regulator. $\operatorname{RsmA}$, an RNA-binding protein, causes translational repression and promotes RNA decay. Our data show that RsmA negatively regulates flhDC and fliA expression. Moreover, the chemical stabilities of transcripts of these genes are greater in an $\operatorname{RsmA}^{-}$mutant than in $\operatorname{RsmA}^{+}$bacteria. These observations contrast with positive regulation of $f l h D C$ and motility by $\operatorname{Csr} A(=\operatorname{RsmA})$ in Escherichia coli. In the absence of AHL, the AHL receptors ExpR1/ExpR2 (= AhIR) in Erwinia carotovora subsp. carotovora negatively regulate motility and expression of $f l h D C$ and $f l i A$ by activating RsmA production. In the presence of $\mathrm{AHL}$, regulatory effects of ExpR1/ExpR2 are neutralized, resulting in reduced levels of $\operatorname{rsm} A$ expression and enhanced motility.
\end{abstract}

Flagellar motility contributes to virulence of several animal pathogens and plant-pathogenic bacteria, including Erwinia carotovora (Josenhans and Suerbaum 2002; Matsumoto et al. 2003; Hossain et al. 2005; Gauger et al. 2007). Evidence for this in E. carotovora subsp. carotovora comes from $\triangle f l i C$ and $\triangle$ motA mutants of E. carotovora subsp. carotovora EC1 (Hossain et al. 2005). These nonmotile mutants were reduced in their ability to cause soft-rotting disease in Chinese cabbage. Although the flagellar regulon of E. carotovora subsp. carotovora has not been fully characterized, extensive studies in Escherichia coli and Salmonella typhimurium serve as a good guide in predicting the structural and regulatory features. The flagellar regulon in E. coli and Salmonella spp. consists of

Corresponding author: A. Chatterjee; Telephone: +1.573.882.1892; Fax: +1.573.882.1467; E-mail: chatterjeeas@missouri.edu approximately 50 genes organized into at least 14 operons and in a three-tier hierarchy: class I, class II, and class III genes (Aizawa and Kubori 1998; Claret and Hughes 2000; Soutourina and Bertin 2003; McCarter 2006). flhD and flhC are the class I genes, whose products are known to form an FlhD $\mathrm{C}_{2}$ hexamer complex (Wang et al. 2006). Both FlhD and FlhC subunits are essential for effective transcription. The FlhDC complex binds promoter regions of the class II genes and activates their transcription (Liu and Matsumura 1994). Within the class II flagellar regulon are genes for proteins for the basal body and the hook of the flagellum as well as two regulators, FliA and FlgM. FliA is an alternative $\sigma$ factor $\left(\sigma^{28}\right)$ specific for the flagellar regulon and FlgM acts as an anti- $\sigma$ factor that inhibits FliA-dependent transcription by stripping FliA from the core of RNA polymerase as well as by preventing the $\sigma$-core interaction (Chadsey and Hughes 2001; Aldridge et al. 2006). FliA is required for the expression of several class II genes and all class III genes. The class III genes specify components for assembly of the flagellar filament, chemotaxis proteins, and motor activity (Aizawa and Kubori 1998; Claret and Hughes 2000; Aldridge et al. 2006; McCarter 2006).

In addition to the flagellar genes for swimming motility, the flagellar master operon FlhDC in E. carotovora subsp. carotovora controls an array of traits, including virulence, type III secretion system, and extracellular enzyme production (Cui et al. 2008). Matsumoto and associates (2003) showed that the FlhC and FlhD deficiencies in E. carotovora subsp. carotovora EC1-N resulted in reduced levels of transcripts of fliC and fliA, flagellum synthesis, and virulence in Chinese cabbage and potato. We subsequently documented that this pleiotropic effect of FlhDC deficiency results from reduced expression of gacA, $r s m C$, and fliA and increased expression of hexA: FliA is responsible for the expression of flagellar genes and bacterial movement (Cui et al. 2008); HexA, an LrhA homolog, is a LysR-like regulator and negatively regulates FlhDC, GacA, and $r s m B$ RNA (A. Chatterjee, unpublished) (Mukherjee et al. 2000); GacA, a response regulator of a two-component system, positively regulates $\mathrm{rsmB}$ (Cui et al. 2001); and RsmC specifies an FlhD-binding protein and behaves as an antiFlhD4FlhC2 factor (Chatterjee et al. 2009). There are reports of FlhDC-mediated control of other traits in several enterobacteria (Givskov et al. 1995; Liu et al. 2000; Blevels et al. 2002; Kapatral et al. 2004). Thus, it is safe to conclude that, in many enterobacteria, including E. carotovora subsp. carotovora, FlhDC behaves as a global positive regulator. 
Expression of $f l h D C$ genes is controlled by environmental cues and several regulators (Aizawa and Kubori 1998; Wei et al. 2001; Lehnen et al. 2002; Sperandio et al. 2002; Soutourina and Bertin 2003; McCarter 2006). One such regulator in Escherichia coli is CsrA (Wei et al. 2001). It is an RNA-binding protein, generally responsible for translational repression and RNA decay. Surprisingly, it was shown to positively regulate flhDC expression (Wei et al. 2001), although the molecular basis for this regulation remains unclear. In Erwinia carotovora subsp. carotovora, this post-transcriptional regulator, designated RsmA (= CsrA), plays a central role in the production of $\mathrm{N}$-acylhomoserine lactone (AHL) and extracellular enzymes or proteins and virulence. In a series of studies, we have determined that RsmA, thus far without any exception, negtively controls gene expression (Chatterjee et al. 1995; Cui et al. 1995; Mukherjee et al. 1996). Thus, the observation in Escherichia coli regarding the positive regulation of $f l h D C$ by CsrA (RsmA) was unexpected. This apparent anomaly prompted us to examine the role of RsmA on FlhDC expression in Erwinia carotovora subsp. carotovora. The data presented here show that, contrary to the positive effect of CsrA in Escherichia coli, RsmA negatively regulates FlhDC in Erwinia carotovora subsp. carotovora. We also document that AHL positively controls motility, and this effect is mediated by the negative effect of AHL on $r \operatorname{sm} A$ expression.

\section{RESULTS AND DISCUSSION}

\section{RsmA differentially affects $f l h D C$ expression and motility} in E. carotovora subsp. carotovora and Escherichia coli.

Wei and associates (2001) reported that expression of flhDC in Escherichia coli is positively regulated by CsrA, the homolog of RsmA. This result was unexpected because RsmA and its homologs have been found to be responsible for translational repression and RNA decay. Consistent with these modes of action, RsmA and RsmA-like proteins are known to negatively control many genes in different bacterial species (Chatterjee et al. 1995; Cui et al. 1995; Muhkerjee et al. 1996; Romeo et al. 1998; Babitzke and Romeo 2007; Lapouge et al. 2008). Therefore, it was of interest to determine whether RsmA positively regulated flhDC in Erwinia carotovora subsp. carotovora as well. We compared the levels of flhDC transcripts of E. carotovora subsp. carotovora Ecc71 and its $\mathrm{RsmA}^{-}$mutant, AC5071. The levels of flhDC transcript in strain $\mathrm{RsmA}^{-}$were higher than that in the parent strain (Fig. 1A). By contrast, the levels of FlhDC transcripts were higher with the $\mathrm{CsrA}^{+}$Escherichia coli BW3414 compared with the levels in its $\mathrm{CsrA}^{-}$derivative TR1-5 (Fig. 1B), as previously reported by Wei and associates (2001).

Wei and associates (2001) had also observed a positive effect of CsrA on motility in Escherichia coli. To our surprise, preliminary motility tests revealed that Ecc71, the wild-type strain we

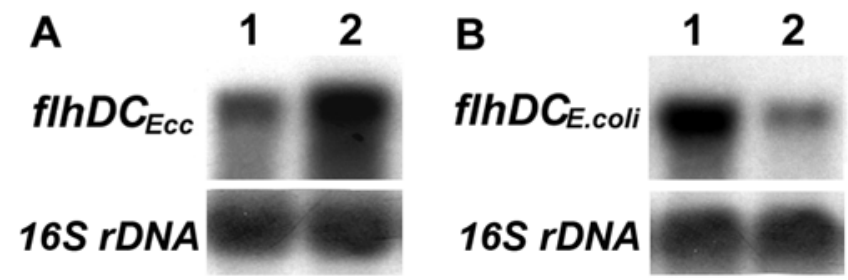

Fig. 1. Effects of RsmA/CsrA on transcript levels of flhDC in Erwinia carotovora subsp. carotovora and Escherichia coli. A, Northern blot analysis of flhDC of 1, Erwinia carotovora subsp. carotovora Ecc71 and 2, its $\mathrm{RsmA}^{-}$mutant AC5071; B, 1, Escherichia coli BW3414 and 2, its CsrAmutant TR1-5. Bacterial cells were grown in King's B medium to a Klett value of approximately 220 for total RNA extraction. Each lane contained $15 \mu \mathrm{g}$ of total RNA. had used in studies of various regulatory systems, exhibits little or no motility. Because it expresses fliA, the gene for flagellumspecific $\sigma$ factor, we presumed that the absence of motility may have resulted from a defect in other class II or class III genes. A comparison of Ecc71 and Ecc7N2, a motile strain, revealed that expressions of fliA and fliE, the gene for flagellar basal body protein are comparable in the two strains (Fig. 2). However, a remarkable difference was seen in the expression of $f l i C$, the gene for flagellin. Whereas Ecc7N2 produces very high levels of fliC RNA, the levels of fliC transcript are low in Ecc71. Thus, it seems plausible that reduced levels of flagellin production may account for the nonmotile state of Ecc71 and its derivatives.

To test the effects of RsmA deficiency on motility in Erwinia carotovora subsp. carotovora, we first constructed an $\mathrm{RsmA}^{-}$ mutant (AC5152) of a motile E. carotovora subsp. carotovora Ecc7N2. Similar to strain Ecc71, deficiency of RsmA in Ecc7N2 causes hyperproduction of exoproteins and hypervirulence (Fig. 3A and B). Motility test results in tryptone swarm agar (Fig. 3C) revealed that the RsmA deficiency of Ecc7N2 leads to hypermotility. Northern blot analysis (Fig. 3D) demonstrated that the transcript levels of flhDC, fliA, fliE, and fliC were higher in the RsmA- mutant AC5152 than in Ecc7N2. These results revealed that, contrary to positive regulation of expression of $f l h D C$ and motility by CsrA in Escherichia coli, in Erwinia carotovora subsp. carotovora, RsmA negatively controls the transcript levels of flhDC and its downstream genes fliA, fliE, and fliC as well as motility.

To further examine whether the differential effects of CsrA and RsmA on expression of $f l h D C$ and motility could be attributed to an intrinsic property of RsmA, we transferred the cloning vector pCL1920 and the Ecc71 rsmA ${ }^{+}$DNA pAKC880 into the $\mathrm{CsrA}^{-}$mutant TR1-5. Northern blot analysis results (Fig. 4A) revealed that TR1-5 carrying pAKC880 produced higher levels of $f l h D C$ and fliA transcript compared with TR1-5 carrying the vector. As would be expected, a motility test in tryptone swarm agar showed that pAKC880 restored motility in the $\mathrm{CsrA}^{-}$mutant (Fig. 4B).

\section{Stabilities of $f l h D C, f l i A, f l i E$, and $f l i C$ mRNAs in $\operatorname{RsmA}^{+}$} and $\mathrm{RsmA}^{-}$E. carotovora subsp. carotovora strains.

Our previous data (Cui et al. 1995) had demonstrated that the high levels of transcripts of exoenzyme genes and $h r p L$, the $\sigma$ factor required for expression of type III effector genes, were due to the greater stability of mRNAs of those genes in the $\mathrm{RsmA}^{-}$strain than in the $\mathrm{RsmA}^{+}$strain. Extrapolating upon

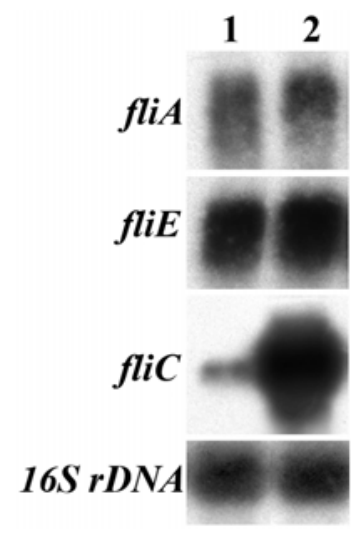

Fig. 2. Transcript levels of fliA, fliE, and fliC in 1, Erwinia carotovora subsp. carotovora Ecc71 and 2, E. carotovora subsp. carotovora Ecc7N2. Bacterial cells were grown in minimal salts plus sucrose medium to a Klett value of approximately 200 for total RNA extraction. Each lane contained $10 \mu \mathrm{g}$ of total RNA. For fliA and fliE, X-ray films were exposed $24 \mathrm{~h}$ at $80^{\circ} \mathrm{C}$ and, for $f l i C$, X-ray film was exposed for $1 \mathrm{~h}$. 

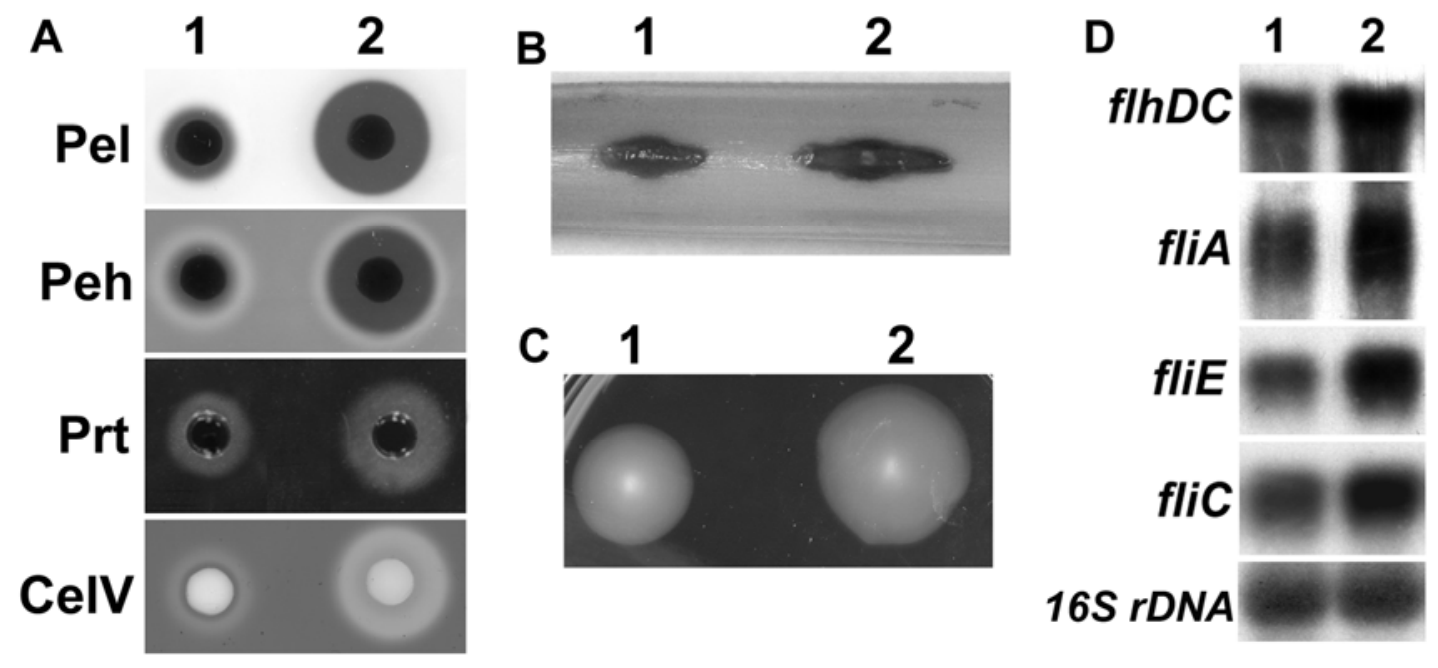

Fig. 3. Characterization of an RsmA ${ }^{-}$mutant of Erwinia carotovora subsp. carotovora Ecc7N2. 1, Ecc7N2 and 2, its RsmA- mutant AC5152. A, Agarose plate assays of pectate lyase (Pel), polygalacturonase (Peh), protease (Prt), and cellulase (Cel) activities. B, Soft-rot disease symptoms in celery petiole. C, Motility in tryptone swarm agar. The inoculated plates were incubated at $28^{\circ} \mathrm{C}$ for $18 \mathrm{~h}$. D, Northern blot analysis of $f l h D C, f l i A, f l i E$, and fliC. Bacterial cells were grown in King's B medium to a Klett value of approximately 220 for total RNA extraction. Each lane contained $15 \mu \mathrm{g}$ of total RNA. For flhDC, fliA, and $f l i E, \mathrm{X}$-ray films were exposed $24 \mathrm{~h}$ at $-80^{\circ} \mathrm{C}$ and, for $f l i C, \mathrm{X}$-ray film was exposed for $1 \mathrm{~h}$.

those observations, we predicted that the higher levels of $f l h D C$, $f l i A, f l i C$, and $f l i E$ transcripts in $\mathrm{RsmA}^{-}$bacteria also were due to greater stability of those transcripts in the $\mathrm{RsmA}^{-}$strain compared with the parent. Indeed, the results in Figure 5 clearly demonstrate that the mRNAs of those genes were more stable in $\mathrm{RsmA}^{-}$strain AC5152 than in the RsmA ${ }^{+}$parent Ecc7N2. These results contrast with those of Wei and associates (2001) in that the $f l h D C$ transcripts were approximately threefold more stable in $\mathrm{CsrA}^{+}$wild-type Escherichia coli versus the $\mathrm{CsrA}^{-}$mutant cells. Of the several fli transcripts, fliC RNA of EccN2 was least susceptible to degradation or processing, and this pattern remained unchanged in the absence of RsmA. The basis for this remarkable stability of $f l i C$ transcripts awaits clarification.

\section{AHL positively controls motility in Erwinia carotovora subsp. carotovora.}

The effects of AHL on motility have been determined in several bacterial species and the results vary depending on the bacterial species. For example, null mutation of AHL biosynthesis has no effect on swimming motility in Pseudomonas aeruginosa (Reimmann et al. 2002), whereas AHL deficiency in Yersinia enterocolitica results in decreased swimming and swarming motility (Atkinson et al. 2006). Recently, Hussain and associates (2008) reported that null mutation of AHL increased swimming and swarming motility of E. chrysanthemi pv. zeae. To examine the effects of AHL on motility in E. carotovora subsp. carotovora, we made an $\mathrm{AhlI}^{-}$mutant of the motile E. carotovora subsp. carotovora Ecc7N2. This AhlI ${ }^{-}$strain, AC5151, was then tested for motility in tryptone swarm agar. The results (Fig. 6A) demonstrate that AHL deficiency of this E. carotovora subsp. carotovora resulted in reduced motility. Northern blot analysis revealed that levels of transcript of $f l h D C$, fliA, and $f l i C$ were lower in the $\mathrm{AhII}^{-}$mutant than in the parent (Fig. 6B). It should be noted that, in contrast to the levels of transcripts of $f l h D C$ and fli genes, the level of $r s m A$ RNA was higher in the $\mathrm{AhlI}^{-}$mutant of Ecc7N2 (Fig 6B). The latter finding was reminiscent of the effects of AHL deficiency in Ecc71 and raised the possibility that the AHL effect on motility may be operating via RsmA.

The AHL receptors ExpR1 and ExpR2 negatively regulate expression of $f l h D C, f l i A$, and fliC in the absence of AHL.

Having established a positive regulatory role of AHL on motility of E. carotovora subsp. carotovora, we focused on the
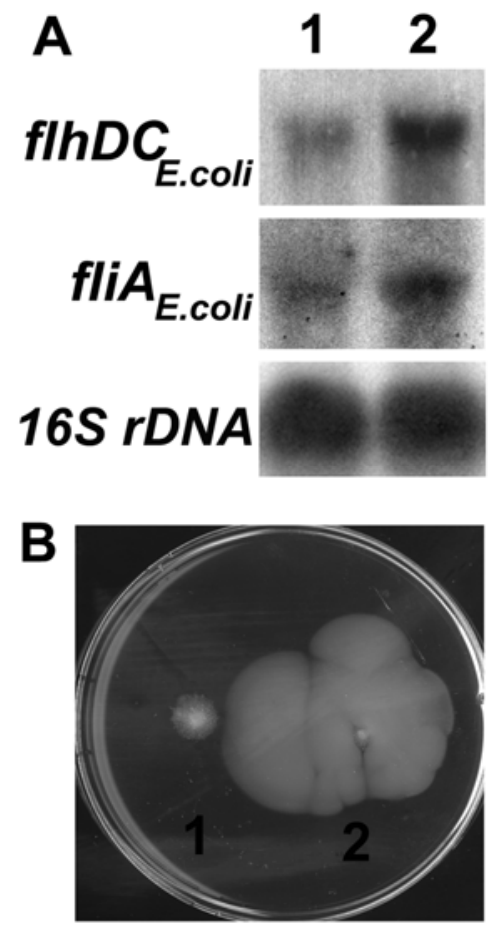

Fig. 4. RsmA of Erwinia carotovora subsp. carotovora Ecc71 restores the transcript levels of flhDC and fliA as well as motility of Escherichia coli

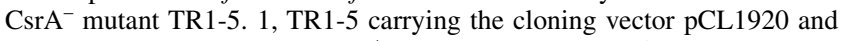
2, TR1-5 carrying the $r s m A_{E c c}{ }^{+}$plasmid pAKC880. A, Northern blot analysis of $f l h D C$ and fliA. Bacterial cells were grown in King's B medium supplemented with spectinomycin to a Klett value of approximately 220 for total RNA extraction. Each lane contained $15 \mu \mathrm{g}$ of total RNA. B, Motility in tryptone swarm agar plate supplemented with spectinomycin. The inoculated plate was incubated at $37^{\circ} \mathrm{C}$ for $48 \mathrm{~h}$.

underlying mechanism. We should recall that the seminal contributions of G. Salmond and T. Palva have established that extracellular enzyme production and virulence are controlled by AHL (Jones et al. 1993; Pirhonen et al. 1993). Subsequent work in our laboratory and elsewhere has clarified the modes of AHL action (Cui et al. 2005, 2006; Sjöblom et al. 2006). In E. carotovora subsp. carotovora, there are two distinct regulatory pathways involving target-specific receptors (Barnard et 


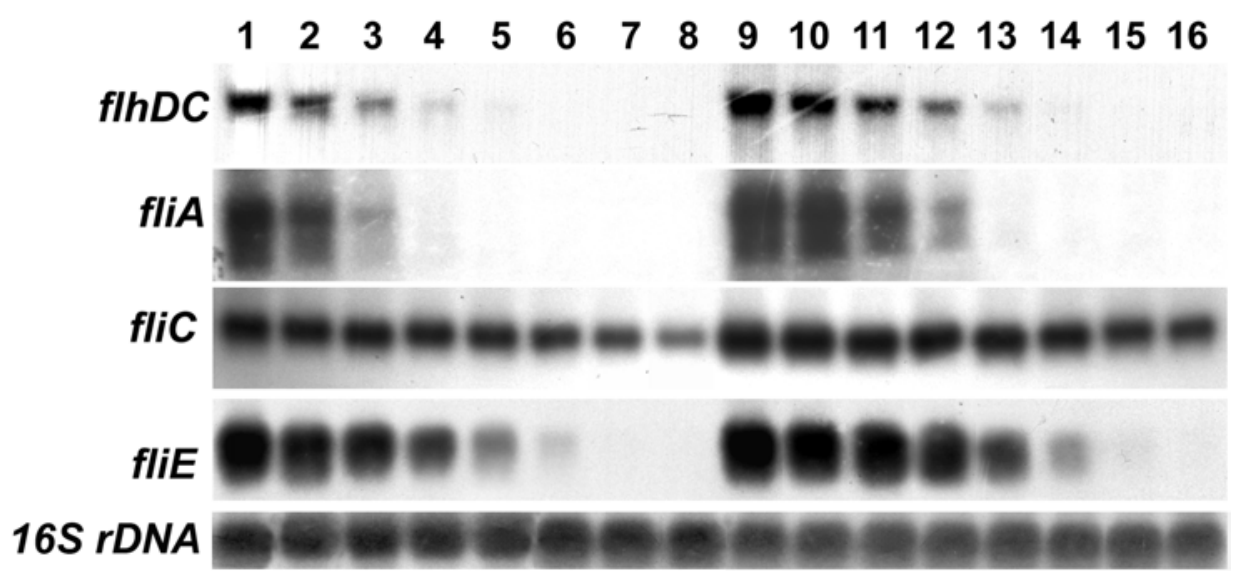

Fig. 5. Stabilities of $f l h D C$, fliA, fliC, and fliE transcripts in Erwinia carotovora subsp. carotovora Ecc7N2 (lanes 1 through 8 ) and its RsmA ${ }^{-}$mutant AC5152 (lanes 9 through 16). Samples were collected at $0,1,2,4,6,8,10$, and $15 \mathrm{~min}$ after the addition of rifampin. Lanes 1 through 8 , each lane contained $15 \mu \mathrm{g}$ of total RNA and lanes 9 through 16 , each lane contained $10 \mu \mathrm{g}$ of total RNA.

A

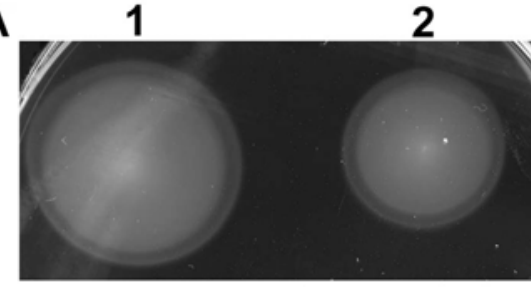

B

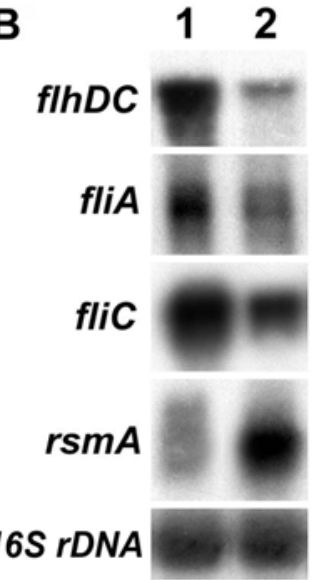

Fig. 6. Effects of AhlI deficiency on motility and expression of $f l h D C$, fliA, fliC, and rsmA in Erwinia carotovora subsp. carotovora Ecc7N2 (Ecc7N2). 1, Ecc7N2 and 2, its AhlI- mutant AC5151. A, Motility in tryptone swarm agar. The inoculated plate was incubated at $28^{\circ} \mathrm{C}$ for $22 \mathrm{~h}$. B, Northern blot analysis of $f l h D C$, fliA, fliC, and $r s m A$. Bacterial cells were grown in King's B medium to a Klett value of approximately 220 for total RNA extraction. Each lane contained $15 \mu \mathrm{g}$ of total RNA. For $f l h D C$, fliA, and $r s m A$, X-ray films were exposed $24 \mathrm{~h}$ at $-80^{\circ} \mathrm{C}$ and, for $f l i C, \mathrm{X}$-ray film was exposed for $1 \mathrm{~h}$.

al. 2007). In a subsets of E. carotovora subsp. carotovora strains, the regulation of antibiotic production follows the LUX paradigm in that CarR, the AHL receptor, binds AHL and this complex activates the antibiotic (carbapenem $=$ Car) biosynthetic (car) genes (Whitehead et al. 2002). To the best of our knowledge, the CarR-AHL complex does not control any other phenotype, including AHL production. The other AHL receptors, ExpR1 and ExpR2 (= VirR) (Sjöblom et al. 2006), activate $r s m A$ transcription in the absence of AHL; this activator function is abrogated upon AHL binding (Cui et al. 2005, 2006). Thus, AHL modulates the levels of RsmA through its effects on ExpR action and, thereby, controls multiple phenotypes of E. carotovora subsp. carotovora. In light of the global

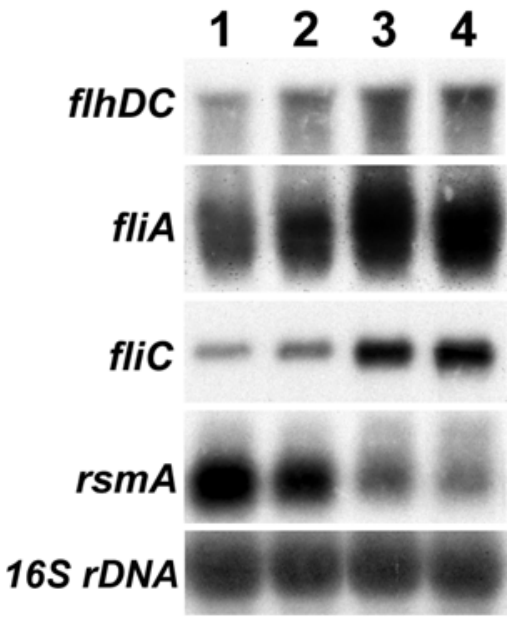

Fig. 7. Effects of ExpR1/ExpR2 on expression of flhDC, fliA, fliC, and rsmA in the absence of $N$-acylhomoserine lactone (AHL). Northern blot analysis of (1) AC5091 (AhlI-ExpR1 $\left.{ }^{+} \operatorname{ExpR}_{2}^{+}\right)$; 2, AC5099 (Ahl ${ }^{\mathrm{I}}$ ExpR1 ${ }^{-}$ ExpR2 ${ }^{+}$); 3, AC5117 (AhlI ${ }^{-} \operatorname{ExpR} 1^{+} \operatorname{ExpR}^{-}$); and 4, AC5118 (AhlI ${ }^{-}$ ExpR $1^{-}{ }^{-} x p R 2^{-}$). Bacterial cells were grown in King's B medium to a Klett value of approximately 220 for total RNA extraction. Each lane contained $15 \mu \mathrm{g}$ of total RNA. For $f l h D C$, fliA, and $r s m A$, X-ray films were exposed $24 \mathrm{~h}$ at $-80^{\circ} \mathrm{C}$ and, for $f l i C, \mathrm{X}$-ray film was exposed for $3 \mathrm{~h}$.

effects of RsmA, including its role in motility (described above), we were led to examine the responses of ExpR (i.e., activators of $r \operatorname{sm} A$ transcription) in the absence of AHL. To study the effects of ExpR1 and ExpR2 on expression of flhDC, fliA, and $f l i C$, we compared the transcript levels of those genes in several mutants of Ecc71: AhlI-ExpR $1^{+}$ExpR2 ${ }^{+}$(AC5091), AhlI $^{-}$ ExpR1 ${ }^{-} \operatorname{ExpR}^{+}$(AC5099), AhlI-ExpR1 ${ }^{+} \operatorname{ExpR} 2^{-}$(AC5117), and AhlI'ExpR1 ${ }^{-}$ExpR2 ${ }^{-}$(AC5118). Aside from the availability of well-characterized mutants, the rationale for using Ecc71 derivatives for this analysis was our finding that the expressions of flhDC and fliA are comparable in both Ecc71 and Ecc7N2 (described above; Fig. 2). Therefore, we predicted that the responses we see with Ecc71 should also apply for Ecc7N2. The results (Fig. 7) revealed that i) the levels of $f l h D C, f l i A$, and $f l i C$ transcripts were slightly higher in the AhlI ${ }^{-}$ExpR $1^{-}{ }^{-E x p R 2} 2^{+}$strain (column 2) than that of $\mathrm{AhlI}^{-}$ ExpR $1^{+}$ExpR2 ${ }^{+}$strain (column 1), ii) the levels of those transcripts were much higher in AhlI-ExpR $1^{+}$ExpR2 $2^{-}$(column 3) and AhlI-ExpR1-ExpR2- (column 4) than that of AhlI $^{-}$ ExpR $1^{+} \operatorname{ExpR} 2^{+}$(column 1), and iii) the levels of flhDC, fliA, and $f l i C$ transcripts correlated with the levels of rsmA tran- 
script in those strains. These observations indicate that both ExpR1 and ExpR2 negatively regulate expression of those genes via stimulation of the expression of $r s m A$. However, ExpR2 compared with ExpR1 is more effective in controlling expression of those genes.

\section{The AHL effect is channeled via RsmA.}

To test whether the AHL effect is channeled via the RsmA pathway, we compared the levels of transcripts of flagellar genes and the degree of motility in $\mathrm{RsmA}^{-}$strains of Ecc7N2 that were either $\mathrm{AhlI}^{+}$(AC5152) or $\mathrm{AhlI}^{-}$(AC5153). The motility assay results (Fig. 8A) revealed that both of those strains are hypermotile compared with the AhlI- $\mathrm{RsmA}^{+}$strain AC5151. Moreover, transcript levels of $f l h D C$, fliA, and $f l i C$ were comparable in the AhlI ${ }^{-}$RsmA ${ }^{-}$and AhlI $^{+}$RsmA $^{-}$strains (Fig. 8B). We should note that these two strains produced similar levels of exoenzymes (Fig. 8C) as well as transcripts of several exoenzyme genes: pel1 , peh-1, and celV (Fig. 8D). We have previously documented that the levels of exoenzymes in $\mathrm{RsmA}^{-} \mathrm{AhlI}^{+}$and $\mathrm{RsmA}^{-} \mathrm{AhlI}{ }^{-}$ mutants of E. carotovora subsp. carotovora Ecc71 are similar (Chatterjee et al. 1995). Thus, in the absence of RsmA, AHL has no effect on motility and exoprotein production, proving that the AHL effect is channeled via RsmA.
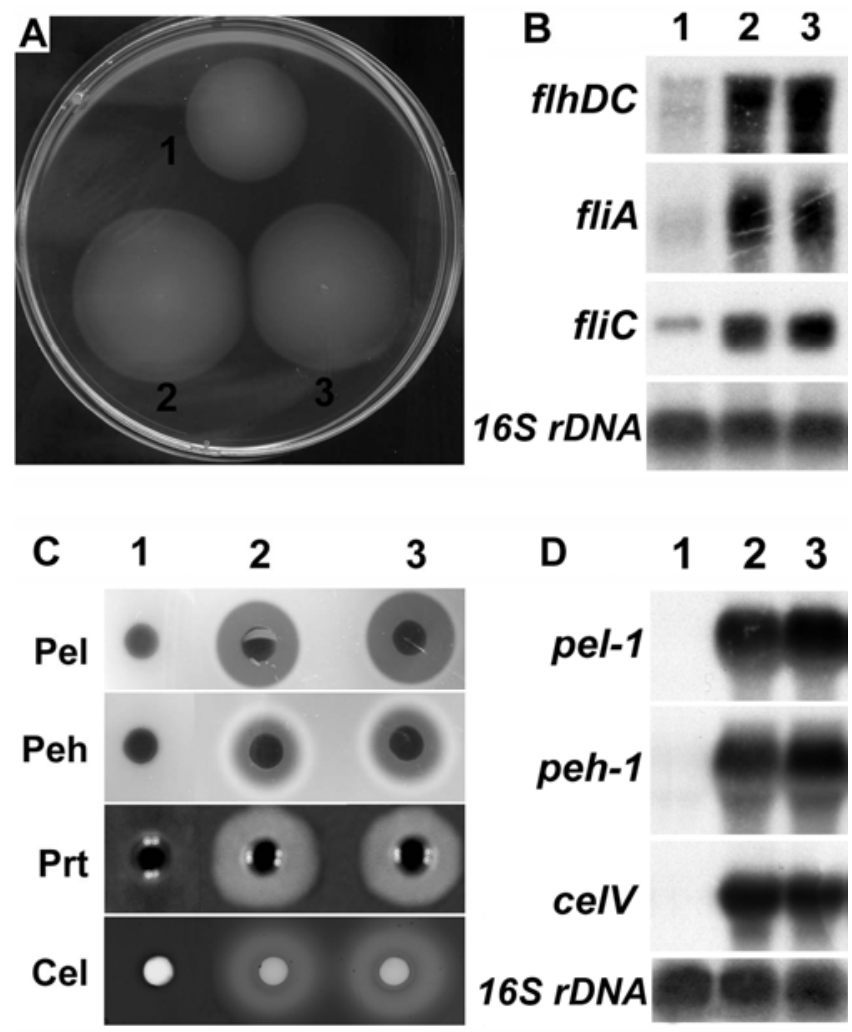

Fig. 8. Effect of $N$-acylhomoserine lactone (AHL) deficiency on motility, exoenzyme production, and expression of flhDC, fliA, fliC, pel-1, peh-1, and celV in the absence of RsmA. 1, AC5151 (AhlI- $\mathrm{RsmA}^{+}$); 2, AC5152 (AhlI $\left.{ }^{+} \mathrm{RsmA}^{-}\right)$; and 3, AC5153 (AhlI-RsmA $\left.{ }^{-}\right)$. A, Motility in tryptone swarm agar. The inoculated plate was incubated at $28^{\circ} \mathrm{C}$ for 22 h. B and D, Northern blot analysis of flhDC, fliA, fliC, pel-1, peh-1, and celV. Bacterial cells were grown in King's B medium to a Klett value of approximately 220 for total RNA extraction for $f l h D C$, fliA, and $f l i C$. For pel-1, peh-1, and celV, RNAs were isolated from bacteria grown in minimal-salts plus sucrose $(0.5 \%$, wt/vol $)$ medium to a Klett value of approximately 220. Each lane contained $15 \mu \mathrm{g}$ of total RNA. For $f l h D C$, fliA, pel-1, peh-1, and celV, X-ray films were exposed for $24 \mathrm{~h}$ at $-80^{\circ} \mathrm{C}$ and, for fliC, X-ray film was exposed for $1 \mathrm{~h}$. C, Agarose plate assays of pectate lyase $(\mathrm{Pel})$, polygalacturonase $(\mathrm{Peh})$, protease (Prt), and cellulase (Cel) activities. Culture supernatants from bacteria grown in minimal-salts plus sucrose medium were used for the plate assays.

\section{Conclusions.}

The findings reported here allow three major conclusions (Fig. 9): motility and flagellar genes are negatively regulated by RsmA and positively regulated by AHL, and the AHL effect is mediated through RsmA involving the actions of the AHL receptors ExpR1 and ExpR2. The RsmA effect manifests itself through modulation of chemical stabilities of transcripts of flagellar genes affecting the levels of RNA species. This effect is consistent with RsmA actions on genes for various exoproteins and their regulators, as previously reported. The evidence presented here also shows that ExpR1/ExpR2, in the absence of AHL, stimulates transcription of $r \operatorname{smA}$. In the presence of AHL, this activity is abolished and, in this manner, AHL modulates the pool of RsmA. In Escherichia coli, RsmA (= CsrA) positively regulates flhDC expression and motility. Our observations are essentially the same as those previously reported by Wei and associates (2001). They found greater stability of flhDC RNA and increased transcription of flhDC-lacZ transcriptional fusion in $\mathrm{CsrA}^{+}$than in $\mathrm{CsrA}^{-}$Escherichia coli strains. The molecular basis for this response is not clear. One possibility is that CsrA binding retards the decay of flhDC RNA, unlike the destabilizing action of RsmA on most other RNA species. The other possibility is that CsrA promotes a

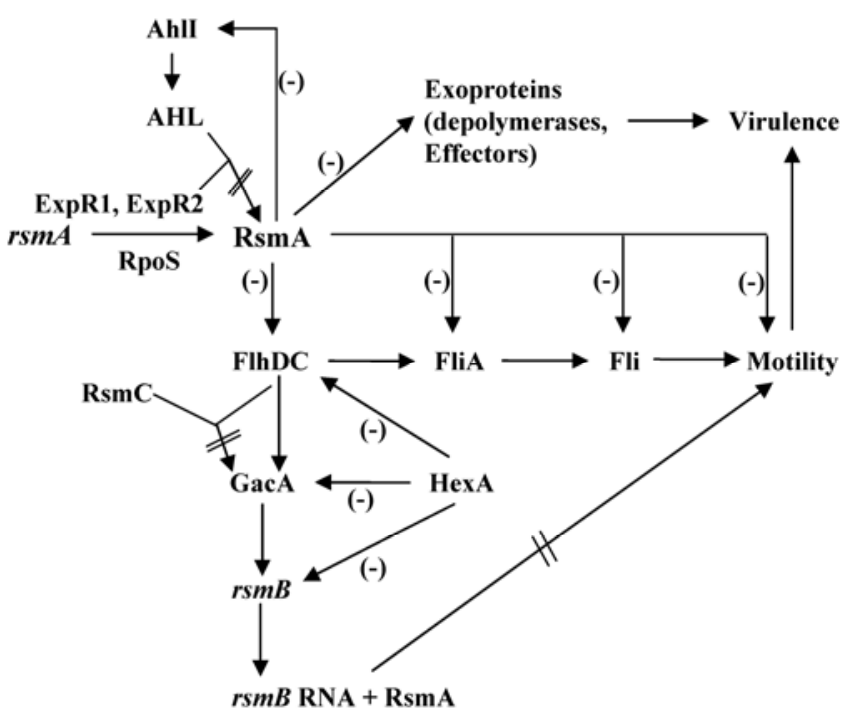

Fig. 9. Model showing motility and flagellar genes are negatively regulated by RsmA and positively regulated by $\mathrm{N}$-acylhomoserine lactone (AHL) in Erwinia carotovora subsp. carotovora Ecc7N2. The AHL effect is mediated through RsmA involving the actions of the AHL receptors, ExpR1 and ExpR2. ExpR1 and ExpR2 bind upstream DNA of rsmA and stimulate $r \operatorname{sm} A$ expression. The activator function of ExpR1 and ExpR2 is abrogated upon AHL binding. Thus, ExpR1, ExpR2, the ExpR1-AHL (3-oxo-C6-HL) complex, and the ExpR2-AHL (3-oxo-C6-HL and 3oxo-C8-HL) complex modulate the levels of RsmA. In addition, RpoS, the stress response $\sigma$ factor, possibly regulates $r s m A$ expression. The RsmA effect manifests itself through modulation of chemical stabilities of transcripts of flagellar genes affecting the levels of RNA species which, in turn, control motility. Motility is also regulated by several positive and negative regulators. Positive regulators are $r \operatorname{sm} B$, an untranslatable RNA that binds RsmA and neutralizes its negative effect $(\mathrm{Rsm}=$ regulator of secondary metabolism); GacA, the response regulator of a widely prevalent two-component system and a positive regulator of rsmB; and FlhDC, the master regulator of flagellar genes, which controls exoprotein production and motility by positively controlling gacA, fliA, and $r s m C$ and negatively controlling hexA (FliA, a flagellum-specific $\sigma$ factor; RsmC, an anti-FlhDC factor, and HexA, a LysR-like protein and a homolog of Escherichia coli LrhA). HexA negatively regulates $f l h D C$, gacA, and $r s m B$ expression (A. Chatterjee, unpublished data), and these repressions are presumed to account for its remarkable effects on quorum sensing-signal and exoprotein production and motility (A. Chatterjee, unpublished data). 
rapid decay of a negative regulator of flagellar genes and this, in turn, stimulates the expression of FlhDC and other flagellar genes. Despite these uncertainties, it is clear that RsmA effects on flhDC in Escherichia coli and E. carotovora subsp. carotovora are fundamentally different.

In E. carotovora subsp. carotovora, motility, a component of the virulence arsenal, is coregulated by RsmA and AHL with extracellular enzymes or proteins, the primary determinants of virulence. This coregulation may be significant in enhancing the disease potential of the pathogen. The actions of secreted enzymes or proteins would cause plant cell death, releasing nutrients for bacterial sustenance. The depletion of nutrients by feeding of the pathogenic bacterium and commensals present at the infection site would necessitate movement of bacteria to a suitable niche to inflict additional damage and nutrient release. This progressive degradation of plant tissue and movement may be critical in disease severity. The pool size of free RsmA and its differential affinity for various RNA species may determine the temporal sequence in which the genes for motility and exoproteins are expressed during the course of disease development.

\section{MATERIALS AND METHODS}

Bacterial strains, plasmids, and media.

Bacterial strains and plasmids are described in Table 1. E. carotovora subsp. carotovora and Escherichia coli strains were maintained on Luria-Bertani (LB) agar. The strains carrying antibiotic markers were maintained on LB agar containing appropriate antibiotics.

The compositions of LB, King's B (KB), and minimal-salts (MM) media have been described in previous publications (Chatterjee et al. 1995, 2003; Murata et al. 1991). When required, antibiotics were supplemented as follows: gentamicin at $10 \mu \mathrm{g} / \mathrm{ml}$, kanamycin at $50 \mu \mathrm{g} / \mathrm{ml}$, spectinomycin at $50 \mu \mathrm{g} / \mathrm{ml}$, and tetracycline at $10 \mu \mathrm{g} / \mathrm{ml}$. Media were solidified using $1.5 \%$ (wt/vol) agar.
The composition of media for agarose plate assays for enzymatic activities was described by Chatterjee and associates (1995).

\section{Motility assay.}

Cells of Ecc7N2, AC5151, AC5152, and AC5153 were stab inoculated into tryptone swarm agar (Harris et al. 1998) and plates were supplemented with spectinomycin for inoculation of bacterial cells harboring pCL1920 or pAKC880. Inoculated plates were incubated at $28^{\circ} \mathrm{C}$ for $22 \mathrm{~h}$ as indicated in the figure legends. Motility of the bacteria was visually examined.

\section{Extracellular enzyme assays.}

Bacterial cells were grown in MM supplemented with sucrose $(0.5 \%, \mathrm{wt} / \mathrm{vol})$ to a Klett value of approximately 250 and the cultural supernatants were used for assays. The semiquantitative pectate lyase (Pel), polygalacturonase (Peh), protease (Prt), and cellulase (Cel agarose plate assays were performed according to previously published procedures (Chatterjee et al. 1995). Briefly, wells were made in agarose media with a no. 2 cork borer and the bottoms were sealed with molten agarose $(0.8 \%$ [wt/vol]). Samples were applied to the wells and the plates were incubated at $28^{\circ} \mathrm{C}$. After 16 to $18 \mathrm{~h}$, Pel and Peh assay plates were developed with $4 \mathrm{~N} \mathrm{HCl}$, and the Cel assay plates were developed with $0.1 \%$ (wt/vol) Congo red and $1 \mathrm{M} \mathrm{NaCl}$ solutions. Halos around the wells due to protease activity became visible in Prt assay plates within 24 to $36 \mathrm{~h}$ without any further treatment.

\section{Plant tissue maceration.}

The celery petiole assay was performed as described by Murata and associates (1991). Bacterial cells $\left(2 \times 10^{7}\right)$ were inoculated into each site. The extent of tissue maceration was estimated visually. For each assay, five different petioles were used and the experiments were repeated at least three to four times. In addition, the positions of the inoculation sites for the parent and the mutant were exchanged to minimize regional differences, if any.

Table 1. Bacterial strains and plasmids used in this study

\begin{tabular}{|c|c|c|}
\hline Strains, plasmids & Relevant characteristics & Source, reference \\
\hline \multicolumn{3}{|l|}{ Strains } \\
\hline \multicolumn{3}{|c|}{ Erwinia carotovora subsp. carotovora } \\
\hline Ecc71 & Wild type & Zink et al. 1984 \\
\hline AC5006 & $\mathrm{Lac}^{-}$derivative of Ecc71 & Murata et al. 1991 \\
\hline AC5071 & $\mathrm{Km}^{\mathrm{r}}, \mathrm{RsmA}^{-}$derivative of Ecc71 & Chatterjee et al. 1995 \\
\hline AC5091 & $\mathrm{Sp}^{\mathrm{r}}, \mathrm{AhlI}-\mathrm{ExpR} 1^{+}{ }^{\mathrm{ExpR}} 2^{+}$derivative of AC5006 & Chatterjee et al. 1995 \\
\hline AC5099 & $\mathrm{Km}^{\mathrm{r}}, \mathrm{Sp}^{\mathrm{r}}, \mathrm{AhlI}{ }^{-} \operatorname{ExpR} 1^{-}{ }^{-E x p R} 2^{+}$derivative of AC5006 & Cui et al. 2005 \\
\hline AC5117 & $\mathrm{Km}^{\mathrm{r}}, \mathrm{Gm}^{\mathrm{r}}, \mathrm{AhlI}-\operatorname{ExpR} 1^{+} \operatorname{ExpR} 2^{-}$derivative of AC5006 & Cui et al. 2006 \\
\hline AC5118 & $\mathrm{Km}^{\mathrm{r}}, \mathrm{Sp}^{\mathrm{r}}, \mathrm{Gm}^{\mathrm{r}}, \mathrm{AhlI}{ }^{-} \operatorname{ExpR} 1^{-} \operatorname{ExpR} 2^{-}$derivative of AC5006 & Cui et al. 2006 \\
\hline Ecc7N2 & Wild type & Lab. collection \\
\hline AC5151 & $\mathrm{Km}^{\mathrm{r}}$, AhlI ${ }^{-}$derivative of Ecc7N2 & This study \\
\hline AC5152 & $\mathrm{Km}^{\mathrm{r}}, \mathrm{RsmA}^{-}$derivative of Ecc7N2 & This study \\
\hline AC5153 & $\mathrm{Km}^{\mathrm{r}}, \mathrm{Sp}^{\mathrm{r}}, \mathrm{AhlI}^{-} \mathrm{RsmA}^{-}$derivative of Ecc7N2 of Ecc7N2 & This study \\
\hline \multicolumn{3}{|l|}{ Escherichia coli } \\
\hline DH5 $\alpha$ & \$80lacZAM15 A(lacZYA-argF), U169 hsdR17 recA1 endA1 thi-1 & Gibco BRL \\
\hline BW3414 & $\Delta l a c U 169 \operatorname{rpoS}(\mathrm{Am})$ & T. Romeo \\
\hline TR1-5 & $\mathrm{CsrA}^{-}$mutant of BW3414 & T. Romeo \\
\hline \multicolumn{3}{|l|}{ Plasmids } \\
\hline pCL1920 & $\mathrm{Sp}^{\mathrm{r}}, \mathrm{Sm}^{\mathrm{r}}$ & Lerner and Inouye 1990 \\
\hline pAKC781 & $\mathrm{Ap}^{\mathrm{r}}$, peh-1 DNA in pBluescriptSK(+) & Liu et al. 1994 \\
\hline pAKC783 & $\mathrm{Ap}^{\mathrm{r}}$,pel-1 DNA in pBluescriptSK $(+)$ & Liu et al. 1994 \\
\hline pAKC854 & $\mathrm{Km}^{\mathrm{r}}, \mathrm{Tc}^{\mathrm{r}}$, inactivated ahll DNA in $\mathrm{pRK} 415$ & Chatterjee et al. 1995 \\
\hline pAKC 855 & $\mathrm{Sp}^{\mathrm{r}}, \mathrm{Tc}^{\mathrm{r}}$, inactivated ahlI DNA in pRK415 & Chatterjee et al. 1995 \\
\hline pAKC870 & $\mathrm{Km}^{\mathrm{r}}, \mathrm{Tc}^{\mathrm{r}}$, inactivated $r s m A$ DNA in pLARF5 & Chatterjee et al. 1995 \\
\hline pAKC 880 & $\mathrm{Sp}^{\mathrm{r}}, r s m A$ of Ecc71 in pCL1920 & Cui et al. 1995 \\
\hline pAKC882 & $\mathrm{Ap}^{\mathrm{r}}, r s m A$ coding region in $\mathrm{pT} 7-7$ & Mukherjhee et al. 1997 \\
\hline pAKC1034 & $A p^{\mathrm{r}}, 200-\mathrm{bp}$ celV fragment in pGEM-T Easy & Liu et al. 1999 \\
\hline pAKC1246 & $\mathrm{Sp}^{\mathrm{r}}$, plac-fliA in pCL1920 & Cui et al. 2008 \\
\hline
\end{tabular}

${ }^{\mathrm{a}} \mathrm{Km}^{\mathrm{r}}, \mathrm{Sp}^{\mathrm{r}}, \mathrm{Gm}^{\mathrm{r}}, \mathrm{Sm}^{\mathrm{r}}, \mathrm{Ap}^{\mathrm{r}}$, and $\mathrm{Tc}^{\mathrm{r}}$ indicate resistance to kanamycin, spectinomycin, gentamicin, streptomycin, ampicillin, and tetracycline, respectively. 


\section{DNA techniques.}

Standard procedures were used in the isolation of plasmid DNAs, gel electrophoresis, polymerase chain reactions (PCR), DNA ligation, transformation, and electroporation (Sambrook et al. 1989). Restriction and modification enzymes were obtained from Promega Biotec (Madison, WI, U.S.A.). Prime-aGene DNA labeling system (Promega Biotec) was used for labeling DNA probes.

\section{Construction of $\mathrm{AhII}^{-}, \mathrm{RsmA}^{-}$and $\mathrm{AhII}{ }^{-} \mathrm{RsmA}^{-}$mutants of E. carotovora subsp. carotovora Ecc7N2.}

The AhlI- mutant AC5151 was constructed by marker exchange of Ecc7N2 with plasmid pAKC854 which contains inactivated ahlI with flanking DNAs. The RsmA ${ }^{-}$mutant AC5152 was obtained by marker exchange of Ecc7N2 with inactivated rsmA plasmid pAKC870 with flanking DNAs. For making the AhlI-RsmA ${ }^{-}$double mutant AC5153, inactivated ahlI plasmid pAKC855 was used for marker exchange with Ecc7N2. This AhlI $^{-}$mutant was then maker exchanged with pAKC870 to yield AC5153. The procedures for marker exchange have been described in Chatterjee and associates (1995). Inactivation of target genes in mutants was confirmed by Northern blot analysis.

\section{Northern blot analysis.}

Bacterial cultures were grown at $28^{\circ} \mathrm{C}$ in $\mathrm{KB}$ or MM supplemented with sucrose $(0.5 \% \mathrm{wt} / \mathrm{vol})$. Cells in late exponential growth phase were harvested as the cultures reached a Klett value of approximately 200 in MM + sucrose medium or 220 in $\mathrm{KB}$ medium. RNA extractions were done from at least two independently grown cultures. RNA isolation and Northern blot analysis were performed as described by Liu and associates (1994). To determine the stability of $f l h D C$, fliA, fliC, and fliE of Ecc7N2 and its $\mathrm{RsmA}^{-}$mutant AC5152, the bacteria were grown in $\mathrm{KB}$ medium to a Klett value of approximately 200 , at which point rifampin $(0.2 \mathrm{mg} / \mathrm{ml}, \mathrm{wt} / \mathrm{vol})$ was added to block further initiation. Culture samples $(8 \mathrm{ml}$ each) were then withdrawn at various time points into tubes containing $5 \mathrm{ml}$ of ice-cold water, and total RNA was extracted. The probes used were the 183-bp NdeI-SalI fragment of rsmA from pAKC882, 314-bp EcoRV-KpnI fragment of pel-1 from pAKC783, 743bp HindIII fragment of peh-1 from pAKC781, 200-bp EcoRI fragment of celV from pAKC1034, and 811-bp BamHI-HindIII fragment of fliA from pAKC1246. The $f l h D C$, fliC, and fliE of E. carotovora subsp. carotovora as well as flhDC and fliA of Escherichia coli probes were PCR amplified using primers described by Cui and associates (2008) and Chatterjee and associates (2009). Equal loading of RNA was checked by hybridization of the blot with a probe corresponding to $16 \mathrm{~S}$ ribosomal RNA (16S rDNA).

Extracellular enzyme assays, Northern blot, and pathogenicity tests were performed at least twice and the results were reproducible.

\section{ACKNOWLEDGMENTS}

Our work was supported by the Food for the 21st Century program of the University of Missouri. We thank D. W. Emerich for reviewing the manuscript.

\section{LITERATURE CITED}

Aizawa, S. I., and Kubori, T. 1998. Bacterial flagellation and cell division. Genes Cells. 3:625-634.

Aldridge, P. D., Karlinsey, J. E., Aldridge, C., Birchall, C., Thompson, D., Yagasaki, J., and Hughes, K. T. 2006. The flagellar-specific transcription factor, sigma28, is the Type III secretion chaperone for the flagellar-specific anti-sigma28 factor FlgM. Genes Dev. 20:2315-2326.
Atkinson, S., Chang, C. Y., Sockett, R. E., Cámara, M., and Williams, P. 2006. Quorum sensing in Yersinia enterocolitica controls swimming and swarming motility. J. Bacteriol. 188:1451-1461.

Babitzke, P., and Romeo, T. 2007. CsrB sRNA family: Sequestration of RNA-binding regulatory proteins. Curr. Opin. Microbiol. 10:156-163.

Barnard, A. M., Bowden, S. D., Burr, T., Coulthurst, S. J., Monson, R. E., and Salmond, G. P. 2007. Quorum sensing, virulence and secondary metabolite production in plant soft-rotting bacteria. Philos. Trans. R. Soc. Lond. B Biol. Sci. 362:1165-1183.

Bleves, S., Marenne, M. N., Detry, G., and Cornelis, G. R. 2002. Up-regulation of the Yersinia enterocolitica yop regulon by deletion of the flagellum master operon flhDC. J. Bacteriol. 184:3214-3223.

Chadsey, M. S., and Hughes, K. T. 2001. A multipartite interaction between Salmonella transcription factor sigma28 and its anti-sigma factor FlgM: Implications for sigma28 holoenzyme destabilization through stepwise binding. J. Mol. Biol. 306:915-929.

Chatterjee, A., Cui, Y., Liu, Y., Dumenyo, C. K., and Chatterjee, A. K. 1995. Inactivation of rsmA leads to overproduction of extracellular pectinases, cellulases, and proteases in Erwinia carotovora subsp. carotovora in the absence of the starvation/cell density sensing signal, $N$-(3-oxohexanoyl)-L-homoserine lactone. Appl. Environ. Microbiol. 61:1959-1967.

Chatterjee, A., Cui, Y., Yang, H., Collmer, A., Alfano, J. R., and Chatterjee, A. K. 2003. GacA, the response regulator of a two-component system, acts as a master regulator in Pseudomonas syringae pv. tomato DC3000 by controlling regulatory RNA, transcriptional activators, and alternate sigma factors. Mol. Plant-Microbe Interact. 16:1106-1117.

Chatterjee, A., Cui, Y., and Chatterjee, A. K. 2009. RsmC of Erwinia carotovora ssp. carotovora negatively controls motility, extracellular protein production and virulence by binding FlhD and modulating transcriptional activity of the master regulator, FlhDC. J. Bacteriol. 191:4582-4593.

Claret, L., and Hughes, C. 2000. Functions of the subunits in the FlhD(2)C(2) transcriptional master regulator of bacterial flagellum biogenesis and swarming. J. Mol. Biol. 303:467-478.

Cui, Y., Chatterjee, A., Liu, Y., Dumenyo, C. K., and Chatterjee, A. K. 1995. Identification of a global repressor gene, rsmA, of Erwinia carotovora subsp. carotovora that controls extracellular enzymes, $\mathrm{N}$-(3-oxohexanoyl)-L-homoserine lactone, and pathogenicity in soft-rotting Erwinia spp. J. Bacteriol. 177:5108-5115.

Cui, Y., Chatterjee, A., and Chatterjee, A. K. 2001. Effects of the two-component system comprising $\mathrm{GacA}$ and $\mathrm{GacS}$ of Erwinia carotovora subsp. carotovora on the production of global regulatory rsmB RNA, extracellular enzymes, and harpin ${ }_{\text {Ecc. }}$ Mol. Plant-Microbe Interact. 14:516-526.

Cui, Y, Chatterjee, A., Hasegawa, H., Dixit, V., Leigh, N., and Chatterjee, A. K. 2005. ExpR, a LuxR homolog of Erwinia carotovora subspecies carotovora, activates transcription of $r s m A$ which specifies a global regulatory RNA-binding protein. J. Bacteriol. 187:4792-4803.

Cui, Y., Chatterjee, A., Hasegawa, H., and Chatterjee, A. K. 2006. Erwinia carotovora subspecies produce duplicate species of ExpR, LuxR homologs that activate $\operatorname{rsm} A$ transcription but differ in their interactions with $N$-acylhomoserine lactone signals. J. Bacteriol. 188:4715-4726.

Cui, Y., Chatterjee, A., Yang, H., and Chatterjee, A. K. 2008. Regulatory network controlling extracellular proteins in Erwinia carotovora subsp. carotovora: FlhDC, the master regulator of flagellar genes, activates rsmB regulatory RNA production by affecting gacA and hexA ( $\operatorname{lrh} A)$ expression. J. Bacteriol. 190:4610-4623.

Gauger, E. J., Leatham M. P., Mercado-Lubo, R., Laux, D. C., Conway, T., and Cohen, P. S. 2007. Role of motility and the flhDC Operon in Escherichia coli MG1655 colonization of the mouse intestine. Infect. Immun. 75:3315-3324.

Givskov, M., Eberl, L., Christiansen, G., Benedik, M. J., and Molin, S. 1995. Induction of phospholipase- and flagellar synthesis in Serratia liquefaciens is controlled by expression of the flagellar master operon flhD. Mol. Microbiol. 15:445-454.

Harris, S. J., Shih, Y. L., Bentley, S. D., and Salmond, G. P.C. 1998. The hexA gene of Erwinia carotovora encodes a LysR homologue and regulates motility and the expression of multiple virulence determinants. Mol. Microbiol. 28:705-717.

Hossain, M. M., Shibata, S., Aizawa, S.-I., and Tsuyumu, S. 2005. Motility is an important determinant for pathogenesis of Erwinia carotovora subsp. carotovora. Physiol. Mol. Plant Pathol. 66:134-143.

Hussain, M. B, Zhang, H. B., Xu, J. L., Liu, Q., Jiang, Z., and Zhang, L. H. 2008. The acyl-homoserine lactone-type quorum-sensing system modulates cell motility and virulence of Erwinia chrysanthemi pv. zeae. J. Bacteriol. 190:1045-1053.

Jones, S., Yu, B., Bainton, N. J., Birdsall, M., Bycroft, B. W., Chhabra, S. R., Cox, A. J. R., Golby, P., Reeves, P. J., Stephens, S., Winson, M. K., Salmond, G. P. C., Stewart, G. S. A. B., and Williams, P. 1993. The lux autoinducer regulates the production of exoenzyme virulence determinants in Erwinia carotovora and Pseudomonas aeruginosa. EMBO (Eur. Mol. Biol. Organ.) J. 12:2477-2482. 
Josenhans, C., and Suerbaum, S. 2002. The role of motility as a virulence factor in bacteria. Int. J. Med. Microbiol. 291:605-614.

Kapatral, V., Campbell, J. W., Minnich, S. A., Thomson, N. R., Matsumura, P., and Prüss, B. M. 2004. Gene array analysis of Yersinia enterocolitica FlhD and FlhC: Regulation of enzymes affecting synthesis and degradation of carbamoylphosphate. Microbiology 150:2289-2300.

Lapouge, K., Schubert, M., Allain, F. H., and Haas, D. 2008. Gac/Rsm signal transduction pathway of gamma-proteobacteria: From RNA recognition to regulation of social behaviour. Mol. Microbiol. 67:241-253.

Lehnen, D., Blumer, C., Polen, T., Wackwitz, B., Wendisch, V. F., and Unden, G. 2002. LrhA as a new transcriptional key regulator of flagella, motility and chemotaxis genes in Escherichia coli. Mol. Microbiol. 45:521-532.

Lerner, C. G., and Inouye, M. 1990. Low copy number plasmids for regulated low-level expression of cloned genes in Escherichia coli with blue/white insert screening capability. Nucleic Acids Res. 18:4631.

Liu, J. H., Lai, M. J., Ang, S., Shu, J. C., Soo, P. C., Horng, Y. T., Yi, W. C., Lai, H. C., Luh, K. T., Ho, S. W., and Swift, S. 2000. Role of flhDC in the expression of the nuclease gene $n u c A$, cell division and flagellar synthesis in Serratia marcescens. J. Biomed. Sci. 7:475-483.

Liu, X., and Matsumura, P. 1994. The FlhD/FlhC complex, a transcriptional activator of the Escherichia coli flagellar class II operons. J. Bacteriol. 176:7345-7351.

Liu, Y., Chatterjee, A., and Chatterjee, A. K. 1994. Nucleotide sequence and expression of a novel pectate lyase gene (pel-3) and a closely linked endopolygalacturonase gene (peh-1) of Erwinia carotovora subsp. carotovora 71. Appl. Environ. Microbiol. 60:2545-2552.

Liu, Y., Jiang, G.-Q., Cui, Y., Mukherjee, A., Ma, W.-L., and Chatterjee, A. K. 1999. $k d g R_{E c c}$ negatively regulates genes for pectinases, cellulase, protease, harpin $\mathrm{E}_{\mathrm{Ec}}$, and a global RNA regulator in Erwinia carotovora subsp. carotovora. J. Bacteriol. 181:2411-2422.

Matsumoto, H., Umehara, M., Muroi, H., Yoshitake, Y., and Tsuyumu, S. 2003. Homolog of FlhDC, a master regulator for flagellum synthesis: Required for pathogenicity in Erwinia carotovora subsp. carotovora. J. Gen. Plant Pathol. 69:189-193.

McCarter L. L. 2006. Regulation of flagella. Curr. Opin. Microbiol. 9:180186.

Mukherjee, A., Cui, Y., Liu, Y., Dumenyo, C. K., and Chatterjee, A. K. 1996. Global regulation in Erwinia species by Erwinia carotovora rsmA, a homologue of Escherichia coli csrA: Repression of secondary metabolites, pathogenicity and hypersensitive reaction. Microbiology 142:427-434

Mukherjee, A., Cui, Y., Liu, Y., and Chatterjee, A. K. 1997. Molecular characterization and expression of the Erwinia carotovora hrpN $N_{E c c}$ gene, which encodes an elicitor of the hypersensitive reaction. Mol. Plant-Microbe Interact. 10:462-471.

Mukherjee, A., Cui, Y., Ma, W., Liu, Y., and Chatterjee, A. K. 2000. hexA of Erwinia carotovora ssp. carotovora strain Ecc71 negatively regulates production of RpoS and $r s m B$ RNA, a global regulator of extracellular proteins, plant virulence and the quorum-sensing signal, $N$-(3-oxohexanoyl)-L-homoserine lactone. Environ. Microbiol. 2:203-215.

Murata, H., McEvoy, J. L., Chatterjee, A., Collmer, A., and Chatterjee, A. K. 1991. Molecular cloning of an aepA gene that activates production of extracellular pectolytic, cellulolytic, and proteolytic enzymes in Erwinia carotovora subsp. carotovora. Mol. Plant-Microbe Interact. 4:239-246.

Pirhonen, M., Flego, D., Heikinheimo, R., and Palva, E. T. 1993. A small diffusible signal molecule is responsible for the global control of virulence and exoenzyme production in the plant pathogen Erwinia carotovora. EMBO (Eur. Mol. Biol. Organ.) J. 12:2467-2476.

Reimmann, C., Ginet, N., Michel, L., Keel, C., Michaux, P., Krishnapillai, V., Zala, M., Heurlier, K., Triandafillu, K., Harms, H., Défago, G., and Haas, D. 2002. Genetically programmed autoinducer destruction reduces virulence gene expression and swarming motility in Pseudomonas aeruginosa PAO1. Microbiology 148:923-932.

Romeo, T. 1998. Global regulation by the small RNA-binding protein CsrA and the non-coding RNA molecule CsrB. Mol. Microbiol. 29:1321-1330.

Sambrook, J., Fritsch, E. F., and Maniatis, T. 1989. Molecular Cloning: A Laboratory Manual, 2nd ed. Cold Spring Harbor Laboratory Press, Cold Spring Harbor, NY, U.S.A.

Sjöblom, S., Brader, G., Koch, G., and Palva, E. T. 2006. Cooperation of two distinct ExpR regulators controls quorum sensing specificity and virulence in the plant pathogen Erwinia carotovora. Mol. Microbiol. 60:1474-1489.

Soutourina, O. A., and Bertin, P. N. 2003. Regulation cascade of flagellar expression in gram-negative bacteria. FEMS (Fed. Eur. Microbiol. Soc.) Microbiol. Rev. 27:505-523.

Sperandio, V., Torres, A. G., and Kaper, J. B. 2002. Quorum sensing Escherichia coli regulators $\mathrm{B}$ and $\mathrm{C}$ (QseBC): A novel two-component regulatory system involved in the regulation of flagella and motility by quorum sensing in E. coli. Mol. Microbiol. 43:809-821.

Wang, S., Fleming, R. T., Westbrook, E. M., Matsumura, P., and McKay, D. B. 2006. Structure of the Escherichia coli FlhDC complex, a prokaryotic heteromeric regulator of transcription. J. Mol. Biol. 355:798-808.

Wei, B. L., Brun-Zinkernagel, A. M., Simecka, J. W., Prüss, B. M., Babitzke, P., and Romeo, T. 2001. Positive regulation of motility and flhDC expression by the RNA-binding protein CsrA of Escherichia coli. Mol. Microbiol. 40:245-256.

Whitehead, N. A., Byers, J. T., Commander, P., Corbett, M. J., Coulthurst, S. J., Everson, L., Harris, A. K., Pemberton, C. L., Simpson, N. J., Slater, H., Smith, D. S., Welch, M., Williamson, N., and Salmond, G. P. 2002 The regulation of virulence in phytopathogenic Erwinia species: Quorum sensing, antibiotics and ecological considerations. Antonie Leeuwenhoek 81:223-231.

Zink, R. T., Kemble, R. J., and Chatterjee, A. K. 1984. Transposon Tn5 mutagenesis in Erwinia carotovora subsp. carotovora and Erwinia carotovora subsp. atroseptica. J. Bacteriol. 157:809-814. 